\title{
MEDIO NATURAL Y EVOLUCIÓN DEL PAISAJE EN LA RIOJA EN LA EDAD MEDIA
}

\author{
José Ángel García de Cortázar \\ Universidad de Cantabria
}

La evolución del paisaje de la Rioja en la Edad Media constituyó un proceso que, en la larga duración, se caracterizó por dos datos significativos: la progresiva reducción del bosque en beneficio del cereal y el viñedo y el mantenimiento, y aun ampliación, de algunas áreas pequeñas y muy localizadas de huertas en el entorno de las villas de Haro y Logroño y las ciudades de Nájera y Calahorra y en los estrechos valles de los ríos bajorriojanos, lo que exigió una ordenada gestión de los recursos hídricos. Esta evolución, semejante a la de otras muchas regiones españolas, estuvo condicionada, como en éstas, por dos factores: una voluntad social (construida sobre las variables relaciones establecidas entre señores y pobladores de la región) y unos datos físicos muy concretos (relieve, suelos, clima, hidrografía).

De estos dos factores, el primero, la voluntad social, está relacionado directamente con la estructura de poder de la sociedad. Ella es la que, en última instancia, promueve los distintos modelos de organización de los espacios, por tanto, de incidencia antrópica sobre el medio natural. A propósito de estos modelos, será objetivo del historiador medir, por una parte, si fueron totalmente sucesivos o parcialmente simultáneos y, por otra, si su proyección tuvo como escenario un marco exclusivamente local, como, por ejemplo, un valle o una aldea, o, más bien, otro regional o incluso suprarregional. Es evidente que, en cada caso, los agentes sociales debieron ser distintos.

Pero la voluntad social como agente inductor de la transformación de un paisaje tuvo que ver también con tres factores: la densidad de población de cada período considerado, la organización del poblamiento heredada de etapas anteriores y las formas de resolución concretas de las opciones económicas prioritarias de los grupos que controlaban el poder. Los dos primeros factores tuvieron, en la Rioja medieval, inevitablemente valores y manifestaciones diferentes según 
se tratara de áreas de sierra, valle o glacis. Por su parte, la realización concreta de las opciones económicas de los señores, que tuvo su traducción en la presión ejercida por ellos, dependió, a la postre, de su grado de implicación en la dirección general del proceso productivo. En otras palabras, entre los siglos VIII y XV, ¿los señores riojanos buscaron, esto es, promovieron activamente (¿cuándo y cuánto?) el cereal, el viñedo, la huerta, la ganadería o se conformaron con estar a la expectativa (a través de la correspondiente punción de rentas) de lo que los campesinos producían? La respuesta a esta pregunta tiene que ver directamente con el grado de integración que la economía de las tierras riojanas tuvo con economías extrarregionales. Así, un alto grado de integración propiciaría que algunas de las decisiones modificadoras del paisaje de la región pudieran tomarse en la Edad media, como sucede hoy, a muchos kilómetros de aquélla.

Con este conjunto de reflexiones 1 parto al estudio de los procesos de modificación del medio natural que tuvieron por escenario un espacio, el de la Rioja actual, de dimensiones muy precisas. El objetivo final del trabajo es, por tanto, el conocimiento de la evolución medieval del paisaje en la Rioja. Y para alcanzarlo, prestaré atención sucesivamente a: a) el medio físico de la región; b) los agentes de la modificación del medio natural; y c) los escenarios de la evolución del paisaje riojano.

\section{El medio natural de La Rioja: algunos datos elementales}

La Rioja que va a constituir el objeto de mi atención coincide con el territorio de la actual comunidad autónoma de ese nombre. No se trata ni de un homenaje a la división provincial de Javier de Burgos de 1833 ni a la reciente configuración de España como Estado de las autonomías. Se trata de reconocer un escenario que, por una combinación de factores históricos y rasgos geográficos, viene a identificarse con ese espacio de unos cinco mil kilómetros cuadrados. Sus límites son, por el norte, el río Ebro y, por tanto, en la Edad Media, desde 1076, el reino de Navarra; por el este, el reino de Aragón; por el sur, los macizos ibéricos riojano-sorianos; y por el oeste, los límites regionales, que aparecen más difuminados, se hallan en la zona de tránsito entre el valle del Ebro y la Bureba.

1. GARCÍA DE CORTÁZAR, J. Á., "Sociedad rural y medio ambiente en la España medieval: Transformaciones del entorno físico en el reino de Castilla en los siglos VIII a XV", J. PÉREZEMBID, ed., La Andalucía medieval. Actas "I Jornadas de Historia rural y medio ambiente" (Almonte, 23-25 mayo 2000), Huelva 2003, pp. 15-42; GARCÍA DE CORTÁZAR, J. Á., "Sociedad rural y entorno físico: las modificaciones del paisaje en la Castilla medieval", F. SABATÉ, ed., Natura y desenvolupament. El medi ambient a I'Edat Mitjana. Lérida 2007, pp. 251-274. Sugerencias y reflexiones complementarias pueden verse en: Clemente Ramos, J., "Evolución del medio natural en Extremadura (c. 1142-c. 1525)", en pp. 15-56, y FURIÓ, A., "La domesticación del medio natural. Agricultura, ecología y economía en el País valenciano en la baja Edad Media" (pp. 57-103), ambos en J. CLEMENTE RAMOS, ed., El medio natural en la España natural. Actas del I Congreso sobre ecohistoria e historia medieval. Cáceres 2001. 
Estos límites de la Rioja sirven de apoyo ya a elementos de nuestra historia. Ampliemos, por ello, algunos datos. El límite norte, el constituido por el río Ebro, sirvió, históricamente, de frontera entre los reinos de Navarra y Castilla. Sólo en 1463, una parte de los territorios navarros, por tanto, situados al norte de aquel río, pasaron a formar parte del reino castellano. Fueron las tierras de la Sonsierra, articuladas en torno a tres villas: de oeste a este, Labastida, San Vicente de la Sonsierra y Laguardia. La Ilamada Rioja alavesa, por tanto, quedó durante la Edad Media, políticamente, fuera de la Rioja castellana. Ello no sólo explica la localización actual de las fuentes documentales sino que condicionó ya en su momento la expansión del poder a un lado y otro del río Ebro. En este sentido, valdría la pena recordar que la corriente fluvial fue una verdadera frontera en la propia política de expansión de los dominios monásticos. Salvo unas pocas posesiones del monasterio de Irache en el valle bajo del río Iregua y en las proximidades de la villa de $\mathrm{HarO}^{2}$, apenas hay datos de implantación de señoríos navarros en tierras riojanas. Una excepción parcial pudo constituirla el dominio del monasterio cisterciense de Fitero, emplazado prácticamente en la muga de los reinos de Aragón, Navarra y Castilla ${ }^{3}$.

El límite oriental de la Rioja coincidió, también, con la frontera entre los reinos de Castilla y Aragón. De ese modo, la ciudad de Calahorra, sede del obispado que, además de otras tierras, abarcaba las de la Rioja, se hallaba situada a dos kilómetros de Navarra y treinta de Aragón. Ello explica que, durante el siglo XIII, los obispos calagurritanos trataran de escoger otra sede menos próxima a la frontera de los reinos y buscaran, para ello, el apoyo del cabildo de Santo Domingo de la Calzada ${ }^{4}$.

El límite meridional de la Rioja lo constituyen los macizos ibéricos que conforman, de oeste a este, la Sierra de la Demanda, la del Camero Nuevo y la del Camero Viejo. En el mismo sentido, las cimas de las montañas van disminuyendo sus alturas máximas, desde el monte San Lorenzo, 2.271 metros, a la Peña Isasa, en la sierra de Préjano, 1.475 metros, y, de hecho, hasta los macizos que, con una altura entre 600 y 700 metros, limitan el valle del río Alhama, ya en el extremo oriental de la región. La frontera meridional de la región, que hoy está marcada por la divisoria de aguas de las cuencas del Ebro y el Duero, ha permitido incluir dentro de ella la mayor parte de los territorios de las Ila-

2. GARCÍA FERNÁNDEZ, E., Santa María de Irache. Expansión y crisis de un señorío monástico navarro en la Edad Media (958-1537). Bilbao 1989, pp. 38-50, estudia las "Áreas de expansión del dominio" del monasterio, incluyendo seis mapas del proceso. Como sabemos por el caso del monasterio de Celanova, cuyo tumbo, concluido en 1172, no recogió las propiedades monásticas que aquél poseía en Portugal, algunos abadengos ocultaron la memoria de sus posesiones en reinos distintos al de su sede principal.

3. MONTERDE ALBIAC, C., Colección diplomática del monasterio de Fitero (1140-1210). Zaragoza 1978.

4. SÁINZ RIPA, E., Sedes episcopales de la Rioja. Siglos IV-XIII. Logroño 1994. 
madas Cinco Villas (esto es, Ventrosa, Brieva, Mansilla, Las Viniegras y Montenegro), que, históricamente, en época en que la Rioja perteneció al reino de Navarra, se hallaban integradas en el de Castilla ${ }^{5}$.

Por fin, el límite occidental de la Rioja, mucho menos definido geográfica y políticamente que los otros tres, está fijado en la zona de tránsito entre los valles del Oja y el Tirón y la Bureba. De hecho, la documentación del siglo $X$ y aún la del siglo XI, en general, la anterior al año 1076, fecha de incorporación de la Rioja al reino de León y Castilla, mostraba esa zona occidental de nuestro escenario como un área de influencia castellana; o, si se quiere, más exactamente, alavesa-castellana, en cualquier caso, occidental ${ }^{6}$.

Los límites descritos encierran una superficie de unos cinco mil kilómetros cuadrados. Dentro de ella, a los efectos del conocimiento del medio natural, conviene recordar, desde el principio, sobre todo, tres datos. El primero, la elevada altitud media del conjunto de la región. La imagen más generalizada de la Rioja se ha elaborado a partir de la percepción de las suaves lomas, en que se asientan los viñedos y el cereal de la zona del somontano, y de los amplios lechos mayores de los ríos, en que se desarrollan las huertas. Pero no debemos olvidar que más de la mitad de la superficie ocupada por la región se halla situada por encima de los 1.100-1.200 metros. El segundo dato lo constituye la gran diferencia de altitud existente entre las cumbres de los macizos ibéricos y el curso del río Ebro en el corto tramo de cincuenta kilómetros de distancia. El tercero es que, como resultado de los dos anteriores, la región aparece claramente articulada por dos elementos: el curso del río Ebro que la recorre por su lado norte en toda la longitud de oeste a este y los cursos de los ríos que, desde los macizos ibéricos, fluyen en sentido sur-norte hacia el Ebro. Tales ríos, de poniente a levante, son: Tirón, Oja, Najerilla, Iregua, Leza, Jubera, Cidacos y Alhama.

De estos rasgos geográficos cabe ya deducir que el medio natural y, por tanto, la evolución del paisaje de la Rioja se han visto condicionados, desde el punto de vista físico, por una dinámica general, la dialéctica establecida entre la cubeta del Ebro y la sierra, matizada por las desiguales posibilidades brindadas por los valles de los ríos afluentes y por la diferente extensión que alcanza lo que podríamos llamar el somontano, entendiendo por éste las tierras situadas apro-

5. MARTÍNEZ DÍEZ, G., Pueblos y alfoces" burgaleses" de la repoblación. Valladolid 1987; GARCÍA DE CORTÁZAR, J. Á., "Percepción y organización social del espacio en la Castilla del siglo XII", Finisterra (Lisboa) XXIV, no 47 (1989), pp. 5-37.

6. PETERSON, D., Frontera y lengua en el Alto Ebro, siglos VIII-XI, tesis doctoral inédita presentada en la universidad de Burgos en noviembre de 2006. Para la baja Edad Media, se hará eco de esa circunstancia el breve artículo de GUERRERO NAVARRETE, Y., "El papel de la Rioja en la configuración del ámbito económico y jurisdiccional de Burgos. La relación de ambas áreas geo-económicas en la Edad Media", II Coloquio sobre Historia de la Rioja. Logroño 1986, I, pp. 257-263. 
ximadamente entre los 600 y 800 metros de altitud. En otras palabras, podemos sintetizar esta presentación del medio natural de la Rioja recordando que la geografía diseña, para el conjunto de la región, dos propuestas de distribución de los espacios y, por tanto, de las posibilidades de aprovechamientos económicos. La primera tiene como líneas de ordenación el río Ebro en el sentido oeste-este y sus afluentes por la derecha en el sentido sur-norte. La segunda deriva de la secuencia de altitudes de la región y fija, de sur a norte, tres franjas: la sierra, el somontano, la cubeta del Ebro. En la Ilamada Rioja alta, la situada al oeste del valle del río Iregua, la montaña y el somontano se reparten, prácticamente, todo el territorio, dejando una franja muy estrecha para la cubeta. En la Rioja baja, en cambio, sierra y cubeta restringen el desarrollo del somontano ${ }^{7}$.

Estos rasgos han propiciado ciertos comportamientos históricos ${ }^{8}$. En la Rioja alta, la mayor extensión del somontano ha facilitado una cierta articulación global del espacio, desde el curso del Ebro hasta la divisoria de aguas con la cuenca del Duero. En la Rioja baja, el escaso desarrollo de aquél le ha impedido cumplir un papel semejante. El espacio queda menos articulado, más fragmentado en los distintos pequeños valles o en la cubeta del Ebro, de lo que se beneficia, sobre todo, Calahorra. En otras palabras, la articulación espacial en la Rioja alta ha podido realizarse históricamente en beneficio de una localidad que ocupa una posición central en el somontano, como fue Nájera. En cambio, en la Rioja baja, esa articulación se expresó en forma de un rosario de pequeñas áreas dependientes de unos pocos núcleos, apoyado en vías de comunicación que seguían el curso de los ríos. El estudio y los mapas, elaborados por Esther Peña, de los que podríamos llamar centros político-administrativos, esto es, de las localidades que sirvieron de sede del poder a dominantes, seniores y tenentes documentados en la Rioja en los siglos X a XII, traduce literalmente la imagen que puede deducirse de los datos que he resumido de la configuración física del territorio .

7. GARCÍA PRADO, J., "La Rioja como región geográfica", Berceo XXIII (1952), pp. 321 344, y XXIV (1952), pp. 381-419.

8. Por supuesto, desde el punto de vista general de esos comportamientos en la Edad Media, no se puede olvidar el papel del Camino de Santiago, aunque su incidencia en la relación de ecología, concretamente, en la Rioja sea imposible de medir. Recuérdese al respecto el trabajo de GARCÍA DE CORTÁZAR, J. Á., "El Camino de Santiago y la articulación del espacio en Castilla", El Camino de Santiago y la articulación del espacio hispánico, XX Semana de Estudios Medievales (Estella, 26 a 30 de julio de 1993), pp. 157-183; y el de RUIZ DE LA PEÑA, J. I., "La formación de la red urbana en el tramo riojano del Camino de Santiago y las colonizaciones francas (siglos XI-XIII)", .

9. PEÑA BOCOS, E., "Alfoces y tenencias: la Rioja", J. Á. GARCíA DE CORTÁZAR, ed., Del Cantábrico al Duero. Trece estudios sobre organización social del espacio en los siglos VIII a XIII. Santander 1999, pp. 375-411. Véase igualmente FERNÁNDEZ DE LA PRADILLA, Ma C., "La articulación del poder pamplonés en el espacio riojano", J. Á. Sesma Muñoz, coord., Historia de la Ciudad de Logroño. Tomo II. Edad Media. Logroño 1995, pp. 35-52. 


\section{Los agentes de la modificación del medio natural: voluntad social dominante y pobladores de la región}

Sobre el medio natural de la Rioja han actuado los hombres. La medición de la acción antrópica correspondiente a cada período histórico es, sin duda, muy difícil de realizar. Con todo, cualquier intento en ese sentido debería tener en cuenta dos factores generales. Los enunciaremos en forma de preguntas. La primera: ¿las distintas sociedades globales instaladas históricamente en la Rioja han tenido opciones de aprovechamiento del espacio diferentes y, por tanto, han propiciado modificaciones del medio natural en un sentido específico, distinto para cada una de ellas? ${ }^{10}$ La segunda: ¿dentro de cada sociedad global, la voluntad social de modificación del medio y, por tanto, de construcción de sucesivos paisajes, ha sido tan dominante que sólo se ha expresado en una dirección o, por el contrario, ha debido aceptar restricciones por parte de otras voluntades sociales no tan dominantes a escala general del sistema pero sí lo suficiente en algunos de sus espacios sociales?"11

En el caso de la Rioja, la primera pregunta reclama analizar si la sociedad prerromana, constituida por los berones y en su extremo oriental por los vascones, la romana, la musulmana y la feudal navarra y castellana actuaron, de modo deliberado, en favor de una determinada opción de modificación del medio natural. La respuesta a esta primera pregunta es muy difícil, al menos, en lo que se refiere a las sociedades prefeudales. La práctica inexistencia de fuentes escritas, la escasez de prospecciones y, mucho más, de excavaciones arqueológicas y una cierta inseguridad en la interpretación de la toponimia no han permitido avanzar mucho al respecto. Con todo, los escasos datos disponibles y su inserción en modelos antropológicos han sugerido algunas imágenes que pueden bastar a nuestro propósito.

La imagen más sobresaliente se refiere a la posible impronta dejada por la presencia árabe y el dominio musulmán en la Rioja ${ }^{12}$. Por pura lógica, esa impronta fue más intensa cuanto más prolongada resultó la instalación islámica. Ello explica que tal impronta sea más visible cuanto más avanzamos de oeste a este de la región. En efecto, si la tierra del Oja apenas estuvo en manos musulmanas, si las de Nájera (en el valle del Najerilla) y Viguera (en el del Iregua) dejaron de estarlo en 923, las de Calahorra (y Arnedo), sobre el Cidacos, lo estuvieron hasta 1045 y las de Alfaro y Cervera de Río Alhama hasta la conquista cristiana de Tudela en 1119.

10. GARCíA DE CORTÁZAR, J. Á., “Organización social del espacio: propuestas de reflexión y análisis histórico de sus unidades en la España medieval", Studia Historica, Historia Medieval, VI (1988), pp. 195-236.

11. GLICK, T., Cristianos y musulmanes en la España medieval (711-1250). Madrid 1991.

12. SÉNAC, Ph., "El dominio musulmán: primeras investigaciones", J. Á. SESMA MUÑOZ, coord., Historia de la Ciudad de Logroño. II .Edad Media, pp. 19-33. 
Esta secuencia de sustitución de la sociedad islámica por la cristiana explica que las menciones más abundantes de toponimia y antroponimia árabes se localicen en áreas muy precisas de la Rioja ${ }^{13}$. En la alta, en Nájera y sus alrededores y en el bajo valle del Iregua, desde Viguera hasta su desembocadura en el Ebro. En la Rioja baja, abundan en general, y en el entorno de Calahorra, Arnedo, Alfaro y Cervera de río Alhama, en particular. En todos los casos, estos datos que sugieren una mayor densidad de establecimiento musulmán se combinan, sobre todo, en las últimas localidades, con un paisaje parcialmente específico: el constituido por los husun como polos de ordenación de un poblamiento rural en que debieron abundar las almunias y en que la población aparecía instalada a orillas de los ríos y con voluntad de ordenar los recursos hídricos.

Este último dato parece convenirse, también, con otros dos de carácter físico. De un lado, el caudal de los ríos de la Rioja baja es inferior al de los altorriojanos. De otro lado, en el extremo oriental de la región, esto es, el que permaneció más tiempo en manos musulmanas, abundan amplias extensiones de suelos pedregosos y de costras calizas que se alternan con saladares, hecho que ha dejado constancia en la toponimia ${ }^{14}$. Estas circunstancias condicionarían más rigurosamente que en la zona occidental de la región la instalación del poblamiento. En torno a los núcleos poblados bajorriojanos, menos numerosos que los altorriojanos, los campesinos prestarían una especial atención a la horticultura. Al menos, las huertas aparecen con frecuencia en la documentación relativa a Calahorra, después de su paso a manos cristianas, y, sobre todo, su presencia se detecta en los textos que se refieren al valle del río Alhama, donde los cultivos de regadío debieron ser relevantes. En este sentido, conviene recordar que el fuero de Cornago, otorgado a los populatores de Araciel por Alfonso I en 1128, contiene indicaciones sobre las prácticas de riego ${ }^{15}$ y, como piensa Philippe Sénac, es posible que las estructuras empleadas per rigare en la zona de Alfaro fueran creadas por los musulmanes. En resumen, durante el período de dominio islámico, la zona más árida de la Rioja debió ser escenario de esfuerzos de ordenación del regadío. Ello contribuyó a configurar en la región un conjunto de paisajes parcialmente diferentes, que los cristianos heredaron cuando, en un proceso que duró de 923 a 1119, ocuparon la totalidad de la Rioja.

Procede, por ello, plantearse ahora la segunda pregunta que enunciaba antes. La recordaré, acomodándola al escenario de la Rioja. ¿La voluntad domi-

13. GARCíA DE CORTÁZAR, J. Á, "La Rioja alta en el siglo X. Un ensayo de análisis cartográfico sobre los comienzos de la ocupación y explotación cristiana del territorio", Príncipe de Viana 132-133 (1973), pp. 309-335.

14. GONZÁLEZ BLANCO, A., Diccionario de Toponimia actual de la Rioja. Murcia 1987.

15. RODRÍGUEZ DE LAMA, I., Colección Diplomática Medieval de la Rioja (923-1225), II, Logroño 1976, $\mathrm{n}^{\circ} 78$, con fecha del año 1125. Para la data en 1128 véase Fortún Pérez de Ciriza, L. J., "Colección de 'fueros menores' de Navarra y otros privilegios locales (I y II)", Príncipe de Viana 43 (1982), p. 294, nota 1. 
nante en la sociedad feudal hispanocristiana fue tan aplastante que, en los procesos de modificación del medio natural, actuó en una sola dirección, con un solo objetivo (por ejemplo, la agrarización, más aún, la cerealización y viñedización del espacio riojano), o debió pactar esas transformaciones con otras voluntades sociales, que quizá no eran dominantes a escala general del reino pero pudieron serlo a escala de algunas de sus comarcas riojanas? En otras palabras, desde el momento en que la Rioja pasó a manos cristianas, ¿cómo ordenaron los habitantes de la región su acción sobre el medio natural? ${ }^{16}$

Las limitaciones para alcanzar una respuesta segura son bien conocidas. Al fin y al cabo, cuando la única documentación existente para el estudio de la Rioja antes del siglo XIII es la procedente de las instituciones eclesiásticas, no resulta fácil la interpretación de los datos que parecen tener que ver con modificaciones en el paisaje. ¿Los podemos considerar como signos de un crecimiento que obliga a roturar el bosque y a transformar su espacio en campos de cereal o de viñedo o son sólo síntomas de una imposición señorial cada vez más intensa sobre unos campesinos y un terrazgo puesto ya en marcha por éstos? Sin ánimo, o simplemente, sin posibilidad de responder con seguridad a estas preguntas, debemos, en cambio, ampliar nuestras reflexiones. Por un sendero muy concreto: ¿cuál es la identidad de los posibles protagonistas de las decisiones de modificación del medio natural en la Rioja?

Empecemos por recordar quiénes pudieron serlo, al menos, desde un punto de vista estrictamente teórico: los reyes, los monasterios, la sede episcopal, los grandes señores, las villas, las comunidades de valle, los concejos aldeanos. Otorguemos nombres a cada uno de estos apellidos. En primer lugar, los reyes: el rey navarro desde el año 923 o el rey castellano desde 1076. En segundo lugar, los monasterios: desde mediados del siglo X, los de San Millán de la Cogolla ${ }^{17} \mathrm{O}$ de San Martín de Albelda ${ }^{18}$; desde mediados del siglo XI, los de Santa María de Valvanera ${ }^{19}$ y Santa María de Nájera ${ }^{20}$; desde finales del siglo XII, el de Santa

16. GARCÍA DE CORTÁZAR, J. Á., "Organización social del espacio en la Rioja cristiana en los siglos X y XI", J. Á. SESMA MUÑOZ, coord., Historia de la Ciudad de Logroño. II. Edad Media, pp. 53-168.

17. GARCÍA DE CORTÁZAR, J. Á., El dominio del monasterio de San Millán de la Cogolla (siglos X a XIII). Introducción a la historia rural de Castilla altomedieval. Salamanca 1969; Maestro Pablo, I., San Millán de la Cogolla (La Rioja). Ensayo bibliográfico. Logroño 2002.

18. LÁZARO RUIZ, M., "El monasterio de San Martín de Albelda: estrategias en la ocupación del territorio y valoración socioeconómica (925-1094)", VII Semana de Estudios Medievales (Nájera, 29 de julio al 2 de agosto de 1996). Logroño 1997, pp. 353-384.

19. GARCíA TURZA, F. J., El monasterio de Valvanera en la Edad Media (siglos XI-XV). Madrid 1990.

20. CANTERA MONTENEGRO, M. Santa María la Real de Nájera, siglos XI-XIV. Madrid 1987,3 vols. 
María de Cañas $^{21}$ o, en el extremo noroeste de la región, el de Santa María de Herrera $^{22}$, asentado en el término de la villa de Miranda de Ebro ${ }^{23}$. En tercer lugar, la sede episcopal: de Calahorra, pero también, a la vez, por las razones geopolíticas antes apuntadas, de Santo Domingo de la Calzada ${ }^{24}$. En cuarto lugar, los grandes señores ${ }^{25}$ : pensemos sólo a modo de ejemplo en la familia de los Arella$\mathrm{no}^{26} \mathrm{O}$, sobre todo, en la de Haro antes de su extinción a finales del siglo $\mathrm{XIV}^{27}$ y en la de los Velasco ${ }^{28}$, que, en parte, la sustituyó en los mismos escenarios. En quinto lugar, las villas o ciudades: empezando por las de Nájera ${ }^{29}$ y Calahorra $^{30}$

21. AlONSO ÁlvareZ, R., El monasterio cisterciense de Santa María de Cañas (La Rioja). Arquitectura gótica, patrocinio aristocrático y protección real. Logroño 2004.

22. CADIÑANOS BARDECI, I., Monasterios mirandeses: Herrera y San Miguel del Monte. Miranda de Ebro $1999^{2}$.

23. DIAGO HERNANDO, M., "Los señoríos monásticos en La Rioja bajomedieval. Introducción a su estudio", Berceo 131 (1996), pp. 85-107.

24. SÁINZ RIPA, E., Sedes episcopales de la Rioja; Díaz Bodegas, P., La diócesis de Calahorra y La Calzada en el siglo XIII. La sede, sus obispos e instituciones. Logroño 1995.

25. DIAGO HERNANDO, M., "El poder de la nobleza en los ámbitos regionales de la Corona de Castilla a fines del Medievo: las estrategias políticas de los grandes linajes en la Rioja hasta la revuelta comunera", Hispania 223 (2006), pp. 501-546.

26. DIAGO HERNANDO, M., "Implantación territorial del linaje Arellano en tierras camero-riojanas a fines de la Edad Media", Berceo 120 (1991), pp. 65-82; MORENO RAMÍREZ DE ARELLANO, M. Á., Señorío de Cameros y condado de Aguilar. Cuatro siglos de régimen señorial en La Rioja (1366-1733). Logroño 1992.

27. CANAL SÁNCHEZ-PAGÍN, J. Ma, "La casa de Haro en León y Castilla de 1150 a 1250. Cuestiones histórico-genealógicas en torno a cuatro nobles damas", Archivos leoneses 85-86 (1989), pp. 85-98, y "La casa de Haro en León y Castilla durante el siglo XII. Nuevas conclusiones", Anuario de Estudios Medievales 25/1 (1995), pp. 3-38.

28. GONZÁLEZ CRESPO, E., Elevación de un linaje nobiliario en la Edad Media. Los Velasco. Madrid 1981.

29. GARCíA TURZA, F. J., "Morfología de la ciudad de Nájera en la Edad Media", III Semana de Estudios Medievales (Nájera, del 3 al 7 de agosto de 1992). Logroño 1993, pp. 63-88; del mismo autor, "Ciudades y aldeas: Nájera", J. Á. GARCÍA DE CORTÁZAR, ed., Del Cantábrico al Duero, pp. 229-261; GOICOLEA JULIÁN. F. J., "La ciudad de Nájera en el tránsito de la Edad Media a la Moderna: el concejo, el señor y la sociedad política ciudadana", Hispania 205 (2000), pp. 425-452; y del mismo autor, "La ciudad de Nájera en la Baja Edad Media como espacio de poder político y social", J. I. de la IGLESIA DUARTE, coord., Los espacios de poder en la España medieval. XII Semana de Estudios Medievales (Nájera, del 30 de julio al 3 de agosto de 2001). Logroño 2002, pp. 149-179.

30. GOICOLEA JULIÁN, F. J., "Gobierno y sociedad en un núcleo urbano de la Rioja Baja: Calahorra (s. XIII-inicios del XVI)", Espacio, Tiempo y Forma, Historia Medieval, 16 (2003), pp. 107-150; DIAGO HERNANDO, M., "Clérigos y laicos en la lucha por el poder en la ciudad de Calahorra a fines de la Edad Media: los conflictos entre los oficiales del concejo y el cabildo de la catedral", Berceo 148 (2005), pp. 93-124. 
y siguiendo por las de Logroño ${ }^{31}$, Santo Domingo de la Calzada ${ }^{32}$, Haro ${ }^{33}$, Navarrete $^{34}$, Briones, Ocón.

En sexto lugar, las comunidades de valle $u$ otras entidades territoriales amparadas bajo un nombre colectivo o un ejercicio compartido de competencias. Dentro de ese apartado, los documentos riojanos brindan ejemplos de tres modalidades de vinculación. La primera, la de las comunidades de valle ${ }^{35}$ que observamos en el extremo sudoccidental de la región: valle de Oja, valle de Canales, valle de San Vicente ${ }^{36}$. De los tres, el segundo estuvo históricamente más vinculado a las tierras castellanas del alto Arlanza que a las riojanas del valle del Ebro. Y el tercero se halla fuera de los límites regionales aunque constituye punto inevitable de referencia fronteriza, en especial, en los siglos X y XI. La segunda modalidad de vinculación la sugieren algunas palabras que implican noción de comunidad. De este tipo nos encontramos, sobre todo, con tres. Las Villas de Campo ${ }^{37}$, con Fuenmayor a la cabeza, las Cinco Villas, en el alto Najerilla, y los Cameros, que, de aceptar la percepción espacial del redactor de los falsos "Votos de San Millán", a mediados del siglo XII, constituyen la zona montañosa situada al sur del paralelo que une Pedroso, en el valle del Najerilla, con Viguera, en el del Iregua, con Trevijano, en el del Leza, y con Jubera, en el río del mismo nombre ${ }^{38}$.

Y, por fin, los últimos protagonistas posibles de las decisiones de modificación del paisaje serían los concejos aldeanos, esto es, de las numerosísimas aldeas que se desparramaban por la región. Si el Nomenclator de la "provincia de Logroño" del año 1960 inclúa 184 municipios y 278 entidades de población, recordemos que, ya para comienzos del siglo XII, los documentos riojanos habían recogido casi trescientos topónimos de núcleos de poblamiento o de algún tipo de asenta-

31. SESMA MUÑOZ, J. Á., coord., Historia de la Ciudad de Logroño. Tomo II. Edad Media.

32. GOICOLEA JULIÁN, F. J., "Sociedad y relaciones de poder en una ciudad riojana a fines del Medievo: Santo Domingo de la Calzada", Espacio, Tiempo y Forma, Hístoria Medieval, 12 (1999), pp. 243-286.

33. GOICOLEA JULIÁN, F. J., Una villa riojana del linaje Velasco a fines del Medievo. Logroño 1999.

34. GOICOLEA JULIÁN, F. J., "Navarrete a finales de la Edad Media: gobierno y sociedad en una villa riojana de señorío", Berceo 136 (1999), pp. 59-86.

35. DÍEZ HERRERA, C., "El 'Valle', unidad de organización social del espacio en la Edad Media", Estudos Medievais (Oporto), 10 (1993), pp. 3-32; de la misma autora, "El valle como espacio de poder social y político", J. I. de la Iglesia Duarte, coord., Los espacios de poder, pp. 47-67.

36. PETERSON, D., La Sierra de la Demanda en la Edad Media. El Valle de San Vicente (ss. VIII-XII). Logroño 2005.

37. GONZÁLEZ BLANCO, A. y PASCUAL GONZÁLEZ, H., "Las siete Villas de Campo: en torno al origen de algunas estructuras medievales", Cuadernos de Investigación. Historia 9 (1983), fasc. 2, pp. 101-112.

38. GARCÍA DE CORTÁZAR, J. Á., "Percepción y organización social del espacio". 
miento $^{39}$. Aunque prescindamos de unos cuantos pequeños monasterios e iglesias, todavía quedan más de doscientos cincuenta nombres de lo que pudieron haber sido aldeas riojanas en los siglos X a XII. Como sucede hoy, la mancha de entidades de población se hacía más densa en la Rioja alta que en la baja. En el somontano altorriojano, abundaban las aldeas cuyo término no excedía de los cinco kilómetros cuadrados. Una densidad semejante podríamos encontrarla en la zona de confluencia de los ríos Oja y Tirón, en el valle del Cárdenas, en el valle medio del Najerilla, en el bajo valle del Iregua. En el otro extremo del escalafón, los núcleos de montaña, por lo tanto hacia el sur y hacia el este de la región, eran más extensos, a tono con las exigencias de su dedicación ganadera.

El elenco de protagonistas de las posibles decisiones de modificación del medio natural induce una obligada reflexión. En efecto, mientras el rey, los monasterios, en menor medida, la sede episcopal calagurritana o calceatense, o los grandes señores podían ajustar sus decisiones económicas a las circunstancias variables de su implantación en más de una región o comarca, las villas, las comunidades de valle, los concejos aldeanos de la Rioja debían dilucidar sus intereses en el marco estricto de la región. En otras palabras, podríamos decir que debían establecer su particular relación de ecología en el escenario, rigurosamente delimitado, de los kilómetros cuadrados y los rasgos físicos específicos de su término. $\mathrm{O}$, como mucho, de los términos contiguos o de los espacios en proceso de atribución a un concejo o a otro, sobre los que, en cada caso, podían intentar tomar decisiones de modificación del paisaje. En definitiva, el conocimiento de la identidad de los titulares de la gestión de los recursos del espacio riojano, y, por tanto, de sus respectivas bases de poder, sus intereses económicos y sus posibilidades de acción resulta crucial a los efectos de comprender su toma de decisiones en el transcurso de los siglos X a XV en el espacio de cinco mil kilómetros cuadrados que nos interesa.

Precisamente, la combinación de ese conocimiento con el de la distribución del poblamiento en las distintas áreas (sierra, valles, somontano, cubeta del Ebro), con el del número de núcleos y, hasta donde es posible intuirla, con el de la densidad de población en cada una de aquéllas, permite deducir la existencia de varios modelos de comportamiento significativos para la historia de la evolución del paisaje riojano. En concreto, cuatro.

El primer modelo corresponde a la acción de lo que podemos considerar agentes interregionales absolutos. Esto es, de aquellos agentes con intereses, a la vez, en la Rioja y en otra u otras regiones ajenas a aquélla; tales fueron los reyes o las grandes familias nobiliarias, en nuestro caso, los López de Haro o, más tarde, los Velasco. En general, la actuación de estos agentes estuvo presidida por la intención de hacer del territorio riojano una fuente de rentas. Desde el siglo XI a

39. GARCíA DE CORTÁZAR, J. Á., “Organización social del espacio en la Rioja cristiana...", mapas en pp. 73, 105 y 137. 
comienzos del XIV, su actitud dominante debió ser el respeto a las decisiones de los vecinos de villas y aldeas en materia de ordenación del paisaje, de las que aspiraban a beneficiarse por vía de la fiscalidad. Sólo desde comienzos del siglo $\mathrm{XV}$, al compás de la recuperación demográfica de la región, subsecuente a la crisis del siglo anterior, esos agentes, y el caso de los Velasco, sucesores en el título de los Haro, ha sido estudiado por Goicolea en la villa de Haro, intervinieron más activamente en la toma de decisiones de ordenación del paisaje. Como veremos, ellos exigieron determinados cultivos, cierres de fincas, plantación de árboles frutales, ampliación del espacio ganadero a costa de los concejos vecinos, etc. ${ }^{40}$

El segundo modelo es el de los agentes interregionales relativos, representados por aquellas instituciones cuya riqueza y poder estaban asentados en más de una región, aunque prioritariamente su escenario fuera la Rioja. El ejemplo mejor conocido es, sin duda, el del monasterio de San Millán de la Cogolla ${ }^{41}$. Su gestión económica en los siglos $\mathrm{X}$ a XV con consecuencias sobre el medio natural permite distinguir tres etapas. En la primera, entre comienzos del siglo $X$ y finales del XII, el dato relevante lo constituyó su mera sobreimposición sobre el campesinado, que fue el que tomaba las decisiones ecológicas. En la segunda etapa, en nuestro caso, entre comienzos del siglo XIII y mediados del XIV, el monasterio adoptó o, más exactamente, hizo visible la adopción, con seguridad anterior, de tres tipos de decisiones: una opción económica ganadera, una reducción, con la correspondiente densificación, del área de dominio, y una renuncia a la instalación activa en lugares lejanos (que, desde ahora, trató de aprovechar por vía de la fiscalidad o por la de la simple permuta por otros más cercanos). La adopción de este conjunto de decisiones tuvo importantes consecuencias sobre el medio natural de las aldeas en las que el monasterio fortaleció su posición. Al reservarse una parte importante de los espacios ganaderos, estimuló un proceso de agrarización del resto del término y se hizo, mediante compra, con numerosas parcelas, cuya dedicación, en ocasiones, hizo pasar del cereal al viñedo. Sin embargo, fue en una tercera etapa, entre mediados del siglo XIV y finales del siglo XV, cuando la doble dinámica de la exigencia señorial y la crisis demográfica, en parte, abonada por ella, y la posterior recuperación produjo una secuencia de vicisitudes más ostensibles en materia de modificación del paisaje; en especial, en las zonas más próximas a la sede monástica. En efecto, al compás del ciclo crecimiento demográfico-caída-recuperación, fue preciso acomodar los recursos de ganadería y agricultura, con las inevitables consecuencias sobre los usos del espacio.

El tercer modelo está representado por la acción de los que Ilamaremos agentes regionales estrictos. Corresponde a las instituciones que, con sede en la

40. GOICOLEA, F. J., Haro.

41. GARCÍA DE CORTÁZAR, J. Á, El dominio del monasterio de San Millán...; GARCÍA TURZA, F. J., "El monasterio de San Millán de la Cogolla en los umbrales de la crisis: 1200-1300", I. GIL-DÍEZ, coord., Los monasterios de San Millán de la Cogolla. Logroño 2000, pp. 27-46. 
Rioja, dispusieron de bienes raíces y de capacidad de intervención en el medio natural en más de un término municipal, con frecuencia, en más de una comarca. De ese tipo fueron, especialmente, algunos de los monasterios (como Santa María de Valvanera o San Martín de Albelda), pero también podemos incluir en ese modelo la sede de Calahorra o la iglesia de Santo Domingo de la Calzada ${ }^{42}$. De hecho, desde la división de las mensae, episcopal y canonical, y la fijación de los arcedianatos, esto es, desde comienzos del siglo XIII, la economía de cada una de las unidades administrativas diocesanas tuvo un carácter estrictamente regional. Con todo, la actuación de estos dos componentes de la Iglesia, regular y secular, a efectos de incidencia en el paisaje fueron diferentes. La primera, la de los monasterios, tuvo un papel más protagonista que la segunda. La Iglesia diocesana, en efecto, parece que se limitó a asegurarse la percepción de los diezmos y primicias de la producción campesina sin interferir en ella. Sólo en el área más inmediata a las localidades que sirvieron de domicilio a los representantes de esa Iglesia diocesana, esto es, Santo Domingo de la Calzada, Nájera, Logroño y, sobre todo, Calahorra, los intereses económicos del obispo, los canónigos o los arcedianos tuvieron una repercusión en el paisaje. En especial, en la ordenación de los recursos de agua, tanto en forma de molinos como en forma de regadío, por consiguiente, de huertas urbanas.

El cuarto y último modelo de intervención en el paisaje correspondió a la acción de los agentes locales. Pudieron ser ciudades y villas (Calahorra; Nájera; Haro; Santo Domingo ${ }^{43}$, aldeas (Badarán, Cañas), valles (Oja), a través de sus vecinos o de sus concejos. En cada caso, la estructura de poder y la distribución de la riqueza propias de cada comunidad local determinaron los objetivos, formas e intensidad de la acción de los vecinos sobre el medio. En líneas muy generales, los documentos riojanos medievales señalan, a este respecto, tres ras$\operatorname{gos}^{44}$ : a) una ampliación del espacio agrario a costa del bosque, en el que, sin embargo, apenas se testimonian informaciones explícitas, directas, de roturación. Sucede entre comienzos del siglo X y mediados del XI, parece dirigido por los propios campesinos y coincide con otro de delimitación cada vez más precisa del territorio atribuido a cada una de las comunidades locales; b) una ordenación más estricta de los aprovechamientos de los espacios aldeanos orientado y exigido por la intervención de los poderes señoriales en las aldeas, en las que se atribuyen un poder de disposición sobre montes, bosques, aguas. Es la imagen característica de finales del siglo XI en adelante. Se tradujo, socialmen-

42. Referencias en notas anteriores.

43. MARTíNEZ SOPENA, P., "Logroño y las villas riojanas entre los siglos XII y XIV" (pp. 279-322); y GARCÍA TURZA, F. J., "Logroño como centro articulador de su entorno rural" (pp. 323-370), ambos en J. Á. SESMA MUÑ̃Z, coord., Historia de la Ciudad de Logroño.

44. Aunque la obra se refiere más precisamente a la ciudad de Logroño, pueden encontrarse abundantes datos y referencias en SESMA MUÑOZ, J. Á., coord., Historia de la Ciudad de Logroño. 
te, en las conocidas tensiones entre señores y campesinos por la explotación de los recursos de cada término; y, económicamente, en los primeros intentos serios, importantes, sobre todo, desde mediados del siglo XIII, de ordenación más orgánica, más homogénea, del terrazgo; y c) una cierta distensión o, más exactamente, una reconversión, de las tensiones, por efecto de la incidencia de la crisis del siglo XIV, a la que siguió, durante el siglo XV, una pugna entre los agentes de modificación del medio natural más poderosos (concejos de las villas; grandes familias nobiliarias, en ocasiones controladoras de aquéllos; señoríos monásticos) que, a efectos de la historia del medio natural riojano, tuvo como consecuencia la definición más estricta de los espacios de aprovechamiento (en especial, bosques y aguas), lo que, a veces, se tradujo en la elaboración de ordenanzas que regularan su utilización ${ }^{45}$.

\section{Los escenarios de la evolución del paisaje riojano: la sierra, el somontano, la orilla del río Ebro}

Los que hemos Ilamado agentes locales de modificación del medio natural de la Rioja presentaban, respecto a los otros, una característica que resulta esencial en nuestra historia. Estaban asentados en los espacios, en los términos territoriales de cada una de las entidades municipales de la Rioja en los que, en última instancia, se fraguaba la relación de ecología, esto es, la relación directa entre una población y un espacio con vistas a su aprovechamiento ${ }^{46}$. En efecto, a diferencia de los tres modelos anteriores, el último se caracterizó porque sus agentes tenían (o llegaron a tener en el curso de los siglos) estrictamente medidos los kilómetros cuadrados susceptibles de usos alternativos. Podían luchar, $y$, de hecho, lo hicieron, por ampliar el espacio disponible. Mediante la presión o la compra, los señoríos monásticos y, sobre todo, los concejos de algunas villas ensancharon sus territorios: Haro, por ejemplo, lo hizo con la incorporación a su término de algunas aldeas cercanas ${ }^{47}$. Pero, aun con esta ampliación, el espacio seguía teniendo unas

45. Lógicamente, la evolución diseñada siguió unas pautas que encuentran evidente semejanza en otras regiones de los reinos hispánicos medievales. En esas circunstancias, conviene volver sobre los dos trabajos de GARCÍA DE CORTÁZAR, J. Á, referentes a las modificaciones del paisaje rural en el reino de Castilla, ya citados, y buscar una ampliación de sus reflexiones y referencias en: GARCÍA DE CORTÁZAR, J. Á. y MARTÍNEZ SOPENA, P., "Los estudios sobre historia rural de la sociedad hispanocristiana", Historia Agraria. Revista de agricultura e historia rural (Murcia), 31 (2003), pp. 57-83.

46. GARCÍA DE CORTÁZAR, J. Á., "Elementos de definición de los espacios de poder en la Edad Media", J. I. de la IGLESIA DUARTE, coord., Los espacios de poder, pp. 13-46; GARCÍA TURZA, F. J., "Los espacios de poder en la Rioja medieval", J. I. de la IGLESIA DUARTE, coord., Los espacios de poder, pp. 483-509.

47. GOICOLEA, Haro, p. 61. En 1325, Haro compra las aldeas de Briñas, Atamauri y Cuzcurritilla y en 1407 se incorpora la de Naharruri (Casalarreina). 
dimensiones concretas, medibles, por tanto, en última instancia, ofrecía unos límites a la acción de los agentes de modificación del medio natural.

Después de conocida la identidad de tales agentes, vamos a seguir, en este apartado, los resultados de su acción. Y, para ello, a modo de ejemplo, propongo que observemos el desarrollo de ésta en tres escenarios característicos. La sierra o zona de montaña, representada, en este caso, por el curso alto y medio del valle del río Oja. El somontano, caracterizado por los glacis o relieves suavemente ondulados que descienden hacia el Ebro, dentro del cual elegiremos la aldea de Villagonzalo de Badarán. Y el área de influencia inmediata del río Ebro, con el análisis de una villa como Haro, asentada en su orilla. No oculto que se trata de tres espacios locales de la Rioja alta, con lo que la Rioja baja va a quedar un poco menos atendida. Mi mejor conocimiento del territorio y la disponibilidad de mayor abundancia de fuentes relativas a la primera han condicionado mi elección.

Primer escenario, por tanto, la sierra, la montaña. Los datos geográficos los conocemos. Son espacios situados por encima de los mil metros de altitud, en los que el relieve presenta una alternancia entre las cumbres y las faldas de montañas cuya cima se sitúa entre 1.700 y 2.200 metros y el fondo de los valles excavados por los ríos que descienden de los macizos ibéricos hacia el Ebro. Más de la mitad de la Rioja, concretamente, su parte meridional, está caracterizada por una alternancia semejante. De esa extensa superficie, de más de 2.500 kilómetros cuadrados, nos fijamos en las tierras altas del valle del Oja, en el extremo occidental de la región. Se trata de un valle cerrado por este, sur y oeste por las mayores alturas regionales, entre 2.000 y 2.200 metros. El río Oja o Glera lo recorre de sur a norte y, al llegar al somontano, esto es, por debajo de los 800 metros, ensancha el valle tan considerablemente que la sensación visual es que lo difumina y propicia un lecho mayor del río muy amplio y amenazador para las poblaciones asentadas en sus orillas. Ello explica la dificultad de los peregrinos jacobeos para atravesarlo y la tardía instalación humana, desde finales del siglo XII, en el núcleo que se convirtió en la villa de Santo Domingo de la Calzada. Precisamente, en el amplio y suavemente moldeado interfluvio entre Oja y Najerilla, se encuentra una zona relativamente amplia y prácticamente despoblada, de unos cien kilómetros cuadrados de terreno pedregoso al que ya Gonzalo de Berceo se refirió como "Valpirri, un sequero logar".

Desde un punto de vista histórico, el valle del Oja constituyó, sin duda, el escenario de instalación de una comunidad de valle. Tal vez, la única a la que, con bastante seguridad, podemos otorgar ese carácter en la Rioja, aunque otras, como la llamada de las Cinco Villas, a caballo de las sierras de San Lorenzo y Castejón, pudo responder también a ese modelo. En los documentos medievales, el valle del Oja aparecía dotado de una personalidad. Era la terra de rivo de Oia o, en otras ocasiones, el valle de Oggacastro, de vertice montis usque ad Ibe- 
rum flumen, como dirá el redactor de los "Votos" de San Millán, al exigir a los vecinos del valle ciertas cantidades de cera en concepto de censo anual a la abadía ${ }^{48}$. El producto exigido, a mediados del siglo XII, sugería ya un paisaje muy poco modificado. La idea la reforzaba el propio texto de los "Votos" cuando, a propósito del valle de Canales y de las Cinco Villlas, por tanto, de dos espacios de montaña casi fronterizos con los del valle del Oja, decía que sus aldeas silvestria in illo confinio videntur posite. Esto es, parecían localizadas en los confines de la masa forestal de la divisoria de aguas entre el Ebro y el Duero.

La primera mención documental del tramo del valle del Oja al que ahora me refiero, en líneas generales, el situado al sur del estrechamiento del mismo entre las localidades de Santurde y Santurdejo, se produjo a mediados del siglo XI. En efecto, la iglesia de San Salvador en la villa Sancto Georgio Oliacastro cum eadem villa, esto es, la iglesia y la aldea de Santurde formaron parte de la dotación inicial de Santa María de Nájera en $1052^{49}$. En los sesenta años siguientes, tres nuevas referencias sobre el valle vinieron de la mano de otros tantos documentos. Dos de ellos fueron simples donaciones de sendos monasterios. El de San Sebastián, entre Valgañón y Zorraquín, a San Millán de la Cogolla en 108750. El de Santa María de Ubago, un poco aguas arriba de Ezcaray, en 1110, a Valvanera ${ }^{51}$.

La imagen que los dos textos ofrecían del valle del Oja recuerda mucho la que, hacía más de un siglo, habían proporcionado los documentos riojanos referentes al somontano. Esto es, un espacio de aparente vocación ganadera, pero, sobre todo, un espacio en que no constaba la actividad agrícola. En él, además de la posible comunidad de valle instalada, que, por las huellas toponímicas, era de origen vizcaíno-alavés, el rey, en este caso, Alfonso Vl, poseía propiedades, aunque, al parecer, muy limitadas. En cualquier caso, él fue quien realizó las donaciones mencionadas; por lo tanto, el que estimuló a los grandes monasterios riojanos a entrar en el ámbito espacial de una comunidad de valle $y$, al hacerlo, a contribuir al debilitamiento de ésta. Uno de los textos, al menos, el del año 1087, era suficientemente claro: el monasterio de San Millán podía efectuar presuras, crear pesqueras y levantar molinos en los ríos, esto es, el Oja y sus pequeños afluentes. Pese a estas concesiones, el valle no estaba deshabitado. El mismo texto confirmaba al monasterio en la posesión de illum locum

48. UBIETO ARTETA An., Cartulario de San Millán de la Cogolla (759-1076). Valencia 1976, $n^{\circ}$ 22. Sobre la fecha de este documento, GARCÍA DE CORTÁZAR, J. Á., "La construcción de memoria histórica en el monasterio de San Millán de la Cogolla (1090-1240)", J. CORDERO RIVERA, coord., Los monasterios riojanos en la Edad Media: Historia, cultura y arte. Logroño 2005, pp. 85-90.

49. CANTERA MONTENEGRO, M., Santa María la Real de Nájera, l, nº 10, año 1052.

50. LEDESMA RUBIO, Ma L., Cartulario de San Millán de la Cogolla (1076-1200). Zaragoza 1989, nº 153, corrigiendo la fecha [1084] del Becerro.

51. GARCíA TURZA, F. J., Documentación medieval del monasterio de Valvanera (Siglos XI a XIII). Zaragoza 1985, $\mathrm{n}^{\circ} 205$. 
heremum in sumitate fluminis Oggensis. Parece razonable pensar que si el documento subrayaba la condición desierta de un lugar debía ser porque existían otros núcleos habitados en la misma zona. La idea la reforzaba el hecho de que el monarca concedía al monasterio inmunidad para que pudiera poblar la aldea desierta cum homines a se subiectos, con hombres dependientes. De ellos podría percibir los pagos debidos homicidii vel fornicii aut latrocinii vel silvastici. El último vocablo vuelve a sugerirnos la idea de un espacio apenas transformado, de un espacio en estado de silva.

Ochenta años más tarde, en torno a 1165, otro documento vino a sugerir algunos cambios en los usos del espacio y en los agentes intervinientes en su aprovechamiento $^{52}$. En efecto, esa área de silva, habitada, probablemente, por comunidades pastoriles instaladas en diminutas aldeas o, quién sabe si, por razón de trashumancia, sólo con carácter estacional, en cabañas y baccarizas, siguió suscitando el interés económico del monasterio de San Millán. En efecto, el texto sugiere la existencia de una serie de acuerdos entre la abadía y unas cuantas comunidades locales para el aprovechamiento de los pastos comunes o que el cenobio pretendía comunes. Más concretamente, el monasterio acordó cum omnibus villis Oiacastrensibus la regulación de aprovechamientos pastoriles para los ganados ovino y vacuno. De esa forma, a finales del siglo XII, mientras las localidades del somontano o del valle del Ebro mostraban ya sensibles progresos tanto en el proceso de agrarización como en el de individualización político-territorial a escala de villa o de aldea, en el valle del Oja, las condiciones seguían siendo diferentes. Desde el punto de referencia señalado, se caracterizaban por una permanencia de condiciones ecológicas boscosas susceptibles de aprovechamiento ganadero y por un vigor de la comunidad territorial de valle por encima de la local de aldea.

Lo significativo de la historia medieval del valle fue que, siglo y medio más tarde, un documento de 1312 continuaba confirmando la existencia de un desfase cronológico semejante en los desarrollos económicos y sociales del valle del Oja con respecto a las aldeas del somontano. El rey Fernando IV veía también ahora, como su lejano predecesor Alfonso $\mathrm{VI}$, un espacio boscoso y poco poblado. Para estimular la instalación humana, el monarca recurrió a expe-

52. LEDESMA RUBIO, Cartulario de San Millán, no 287 bis, en pp. 401-402. El documento se incluyó en el Becerro sin foliar y antes del índice. Por evidente error tipográfico, su editora propone la fecha de 21 de mayo de 1053, cuando el texto, fechado por el año de la Encarnación, indica MLXIII. En realidad, el documento [pese a su referencia de haberse redactado regnante rege Sancio in Pampilonia et Nagera, filius Garsie strenuisimi regis qui fundavit monaestrium Sancti Emiliani ubi nunc est colocatum] habría que datarlo cien años después, en el abadiato de García, probablemente en 1163 , fecha que se convendría con la del documento ${ }^{\circ}$ 405, de 7 de mayo de 1164, que recoge un texto parecido de acuerdo entre los concejos de Ojacastro, Ezcaray y Valgañón y el abad García de San Millán sobre el cuidado de vacas y bueyes del monasterio. 
dientes que recordaban los utilizados, nada menos que doscientos cincuenta años antes, en la repoblación de villas de frontera como Sepúlveda. En efecto, "porque este valle de la villa de Oojacastro e Escaray e Zurraquin e Valgannon e sus terminos [...] se pueble mejor, es mi merced que los homes e mugeres homicianos e malfechores que se vinieren a acoger en el dicho valle [...], que ninguna justicia non sea osada de entrar"53. En definitiva, la sierra de San Lorenzo, como las de Castejón o los dos Cameros continuaban siendo, a finales de la Edad Media, un espacio boscoso, una reserva para el ganado. No olvidemos que, unos siglos antes, a fines del siglo $\mathrm{XI}$, vecinos de estas tierras altas de los valles del Oja, Najerilla e Iregua habían emigrado hacia las estribaciones del Sistema Central. Allí, como ganaderos altivos, los encontró Ángel Barrios cuando estudió la composición humana de las tierras situadas entre el Duero y la Cordillera central; las tierras de la Extremadura histórica ${ }^{54}$.

Segundo escenario, el somontano. En la Rioja, constituye una franja de unos cien kilómetros de longitud que ocupa las tierras situadas aproximadamente entre los $750 \mathrm{~m}$. y los $500 \mathrm{~m}$. de altitud con una anchura máxima de unos 20 kilómetros en los meridianos de Grañón o de Alesanco y una mínima de unos 10 kilómetros en los meridianos de Ribafrecha o Ausejo. Su disposición en glacis de suave pendiente, que enlazan con las terrazas medias y altas de los distintos ríos, y su composición litológica, en que dominan areniscas y margas, proporciona, salvo en pequeñas áreas de costras calizas, de yesos o, en el extremo oriental de la región, de extensiones excesivamente pedregosas, a las que, sin embargo, puede acomodarse el viñedo, un escenario en que la roturación de la masa arbórea no ha sido especialmente difícil y, por el contrario, ha proporcionado espacios de fácil y rentable utilización agrícola. Una pluviosidad anual que ronda los 500-600 mms., con lluvias predominantemente en primavera, completa las condiciones de desarrollo del somontano riojano.

Esta unidad paisajística, que es la que identificamos mentalmente con la Rioja por antonomasia, es la que ha acogido, históricamente, la mayor densidad de núcleos y, por tanto, en general, los términos municipales más reducidos. Estas condiciones se cumplen, especialmente, en la Rioja alta, en el triángulo Foncea-Grañón-Haro y en el círculo de aldeas en torno a Nájera, mientras que es menos evidente en la Rioja baja, donde, como apunté antes, los núcleos de poblamiento aparecen más vinculados a los fondos de los valles de los afluentes del Ebro o a la primera terraza de éste. De ese mundo de aldeas del somontano, cuyos términos en la Rioja alta no pasaban, con frecuencia, de las cua-

53. MARTíNEZ DíEZ, G., "Fueros de La Rioja”, Anuario de Historia del Derecho Español 49 (1979), no 25, pp. 451-452.

54. BARRIOS GARCÍA, Á., "Repoblación de la zona meridional del Duero. Fases de ocupación, procedencias y distribución espacial de los grupos repobladores", Studia Historica, Historia Medieval, III (1985), pp. 33-82. 
trocientas hectáreas, he seleccionado la de Villagonzalo ${ }^{55}$. Los habitantes de este núcleo, con los de sus vecinos Badarán, Terrero y Villadolquit, se integraron en un solo (el de Badarán), que se rodeó de una cerca por decisión del abad de San Millán en mayo de 1326, en medio de las turbulencias de la crisis del siglo XIV.

El término resultante de esta agregación, el actual Badarán, tiene hoy una superficie de veinte kilómetros cuadrados. Su forma recuerda, muy imperfectamente, la de un rombo atravesado, en el sentido suroeste-este, por el río Cárdenas, afluente del Najerilla. El curso fluvial constituye una especie de eje hacia el que desciende, desde el norte y, más marcadamente, desde el sur, el relieve del término actual. Dentro de éste, la configuración física y los rasgos de los suelos permiten señalar tres áreas. La del norte, de relieve suave, tierra apta para el cereal y el viñedo. La del centro, una estrechísima franja constituida por el lecho mayor del río Cárdenas, muy fértil pero exigente en mano de obra para trabajar las pesadas tierras aluviales. Y la del sur, que asciende hasta un lugar de microtopónimo expresivo ("Guardia"), aparentemente menos dispuesta para la agricultura y más para el desarrollo del bosque.

La primera mención de Villagonzalo data del año 952 y en ella se alude a un uso, mancomunado con Terrero, de los pastos y aprovechamientos ganade$\operatorname{ros}^{56}$. Esa imagen de vocación ganadera se prolongó en el tiempo. Al menos, en 1044, un texto que el copista del becerro del monasterio de San Millán de la Cogolla, señor de la aldea de Villagonzalo, tituló fuero de defesas de Matrice o Madriz (aldea englobada en el actual núcleo de San Millán), volvía a recordar esa circunstancia ${ }^{57}$. Con todo, la necesidad de regular por escrito los usos del espacio boscoso podía ser indicio de que empezaba a preocupar una cierta disminución de los espacios forestales y ganaderos. El documento distingue, al menos, tres situaciones posibles en el ejercicio de los derechos de aprovechamiento de madera, leña y pasto. Recordémoslas ya que pueden resultar orientativas para la historia de otras aldeas del somontano riojano.

En principio, los vecinos de Villagonzalo, como los de las limitáneas aldeas de Cordovín y Terrero, tenían derecho a que sus rebaños pastaran, en comunidad con los de Madriz, salvo en las dehesas que los campesinos de esta última aldea disfrutaban con carácter exclusivo. En un segundo conjunto de dehesas, los vecinos de Villagonzalo, sin derecho a sacar madera o cortar leña, podían enviar sus ganados para que pastaran durante el día, aunque, por la noche,

55. GARCíA DE CORTÁZAR, J. Á., "Aldea y comunidad de aldea en la Rioja medieval: el caso de Villagonzalo (Badarán)", Príncipe de Viana XLVII (1986), anejo 2, Homenaje a José María Lacarra, pp. 191-211. Véase también: GARCíA TURZA, F. J., "Las aldeas de la Rioja medieval. El ejemplo de Villanueva", II Semana de Estudios Medievales (Nájera, 5 al 9 de agosto de 1991). Logroño 2001², pp. 233-241.

56. UBIETO, An., Cartulario de San Millán, $\mathrm{n}^{\circ} 65$.

57. UBIETO, An., Cartulario de San Millán, nº 231. 
debían retornar a los corrales de la aldea. Y, por fin, en un tercero, los aldeanos de Villagonzalo podían incluso levantar cabañas y majadas de modo que sus ganados se refugiaran en ellas de forma más estable. En resumen, el documento del "Fuero de las defesas de Matrice" parecía constituir un instrumento de defensa de los espacios forestales y ganaderos, síntoma de su progresiva reducción. Cinco años más tarde, dos testimonios complementarios rubrican tanto la orientación, hasta ese momento, ganadera de la aldea como sus dificultades para mantenerla ante la presión roturadora. De un lado, en 1049, el rey navarro García Sánchez III condonó a Villagonzalo, Cordovín y Terrero la prestación de transporte de madera al palacio real previa entrega de ochenta vacas, seiscientos carneros y cien puercos ${ }^{58}$. De otro lado, por estas mismas fechas, Villagonzalo constituía su propia dehesa en lo que será el extremo noroccidental de su término, frontero con la Rad de Villar de Torre.

Hacia finales del siglo XI, el aumento de la documentación permite ver con mayor seguridad un cambio en el paisaje de Villagonzalo ${ }^{59}$. Para esas fechas, las manchas boscosas de las dehesas de glandíferos se habían reducido y ocupaban el círculo más exterior del término, donde constituían, al menos, se apreciaba claramente en el oeste, su límite con los de Cañas, Villar de Torre y Madriz. Fue en esos espacios, precisamente, donde tanto hacia los años 1100 como, sobre todo, un siglo después, los campesinos de Villagonzalo trataron de adquirir, mediante roturación, unos espacios para sus campos de cereal y, en menor medida, su viñedo. Esa imagen de aprovechamiento heterogéneo del círculo exterior del término de Villagonzalo (bosque de robles; cereal; viñedo) se simplifica conforme nos acercamos al núcleo poblado.

En ese otro círculo interior, además de los linares instalados en la orilla de varios arroyos o del río Cárdenas, nos encontramos con dos espacios que apuntaban ya dedicaciones económicas más homogéneas. De un lado, el de las que habían sido las sernas de Avantines y Roxo, orientado al cereal. De otro lado, Badarán, nombre aparecido en 1090 y que, en los dos siglos siguientes, denominará al principal pago de viñedo del término. En uno y otro espacio, los documentos de los siglos XII y XIII y la fijación de algunos topónimos acreditan una especialización en las dedicaciones, con una tendencia a reservar áreas del término a cada uno de los dos cultivos dominantes, el trigo y la vid. Por su parte, la estrecha banda de suelos aluviales del lecho del río Cárdenas propiciaba la instalación de los linares y de las huertas. Villagonzalo adquiría así una diversificación de orientaciones económicas que fue, sin duda, estimulada y aprove-

58. UBIETO, An., Cartulario de San Millán, no 256.

59. El proceso, general en la Rioja alta, fue analizado y valorado por GARCÍA DE CORTÁZAR, J. Á., "Crecimiento demográfico y ordenación del espacio en la Rioja alta en el siglo XI", Anuario de Estudios Medievales, 15 (1985), pp. 63-83. 
chada por su señor, el abad del monasterio de San Millán de la Cogolla, situado a una hora de distancia a pie.

El tercer escenario escogido para el análisis de las relaciones entre población y medio natural en la Rioja ha sido el área de influencia directa del río Ebro, su cubeta en sentido estricto. Y, dentro de los cien kilómetros de su recorrido riojano, he seleccionado el término de una villa altorriojana, la de Haro ${ }^{60}$. De esa forma, después de un escenario de valle de montaña y otro de aldea de somontano, observaremos la dinámica de una villa asentada en la confluencia y en la orilla derecha de los ríos Tirón y Ebro. A la vez, cambiamos también de cronología; de la mano del estudio de Francisco Javier Goicolea, nos adentramos en la baja Edad Media para estudiar especialmente la evolución del paisaje de Haro en el siglo XV.

Antes de esa fecha, la zona de Haro, puerta de entrada del Ebro en la Rioja por las conchas de Bilibio y Buradón, había conocido una historia muy semejante a la numerosos núcleos altorriojanos. Tras la ocupación cristiana de la Rioja, Bilibio y Buradón sonaron como asiento de tenentes y dominantes, papel en el que Haro los irá sustituyendo desde mediados del siglo XI. Por las mismas fechas, las grandes abadías de San Millán de la Cogolla y Santa María de Irache recibieron en donación propiedades en la zona, incluido algún pequeño monasterio. Con todo, la imagen proporcionada por los documentos hasta mediados del siglo XII era la de una escasa intervención de esos agentes señoriales en la zona harense.

En 1187, la aldea de Haro, por decisión de Alfonso VIII, se convirtió en villa dotada de un fuero de los llamados de francos, inspirado, aunque con texto independiente, en el de Logroño. Por debajo de las cláusulas generales que conocemos, el texto foral parecía subrayar una orientación social y tres económicas. La primera, explicable por la situación fronteriza de la plaza frente al reino de Navarra, es la militar. Las otras, que interesan más a nuestro argumento, eran: la actividad mercantil, la agricultura y, más expresamente, la derivada de la explotación que se concedía a los pobladores en omnibus montibus de Bilivio et de Faro y en montibus et hereditate de Valpierre, aquel "Iogar sequero", de que Gonzalo de Berceo hablará años más tarde. En consecuencia, a tenor del fuero, Haro iba a disponer de un término de unos setenta kilómetros cuadrados de extensión.

En los años que siguieron a la concesión del fuero, la población de la villa intensificó la explotación agraria del entorno del núcleo, pero, a la vez, tuvo que empezar a hacer frente a las pretensiones de aprovechamiento ganadero de los montes de Bilibio que esgrimió el monasterio cisterciense de Santa María de Herrera, fundado casi por las mismas fechas ${ }^{61}$. Los enfrentamientos por esa razón entre la abadía y la villa de Haro se recrudecieron a mediados del siglo XIII y se complicaron por la intervención del concejo de Miranda de Ebro, en

60. GOICOLEA, Haro.

61. CADIÑANOS, Monasterios mirandeses, pp. 9-126. 
cuyo término había nacido el monasterio de Herrera, y que tampoco estaba dispuesto a renunciar a sus intereses ganaderos en los montes de Bilibio ${ }^{62}$. La discusión se centraba, por tanto, en la defensa de un espacio ganadero y en la pretensión de su uso en exclusiva por las partes contendientes. Los diversos intentos de acuerdo entre éstas, que se prodigaron en la segunda mitad del siglo XIII, sólo fructificaron a mediados del siglo XIV cuando los concejos de las dos villas y el monasterio acordaron realizar la división y el reparto de la llamada dehesa de San Llorente. Casi por los mismos años, en 1347, la villa de Briones aceptaba la sentencia que había dictado que Haro había comprado hacía poco tiempo la aldea de Cuzcurritilla a los efectos de ampliar su término.

A pesar de las protestas de Santa María de Herrera, que estimó que el acuerdo sólo servía para asegurar los derechos de Haro y Miranda a costa de los suyos, la segunda mitad del siglo XIV pareció caracterizarse por una distensión de los enfrentamientos por los montes de Bilibio. Sin embargo, desde principios del siglo XV, los datos empezaron a revelar un aumento de la presión de la población de Haro sobre el espacio ${ }^{63}$. En 1407, la villa amplió su término en unos diez kilómetros cuadrados al incorporarse, mediante contrato de arrendamiento suscrito con el monasterio de Santa María de Cañas, la aldea de Naharruri, actual Casalarreina, a orillas del río Oja y con excelentes posibilidades de explotación de un terrazgo fácilmente diversificable en que los cultivos de regadío podían tener un cómodo desarrollo ${ }^{64}$. En los años siguientes, la emigración de campesinos de los dominios señoriales cercanos a los términos de las villas altorriojanas, entre ellas, la de Haro, benefició en concreto a su aldea de Naharruri, que, según el padrón del año 1512, era la más poblada y rica del alfoz ${ }^{65}$.

Los síntomas de recuperación de los efectivos demográficos de Haro y su término, visibles desde comienzos del siglo $\mathrm{XV}$, se aceleraron a partir de mediados de la centuria. Entre ellos, dos tuvieron especial incidencia en la evolución del paisaje. El primero, los repartos de "suertes" que se llevaron a cabo entre los vecinos del núcleo urbano y de las aldeas para el aprovechamiento de los pagos de Zaballa y Tondón. El segundo, la ordenación de los aprovechamientos de los mon-

62. GARCÍA DE CORTÁZAR, J. Á., "Medio natural e historia medieval: Miranda de Ebro y su entorno (siglos VIII-XVI)", J. CLEMENTE RAMOS, ed., el medio natural en la españa medieval, pp. 105-139.

63. El fenómeno, con sus diferencias cronológicas, fue muy general: DÍAZ DE DURANA, J. R., "La recuperación del siglo XV en el Nordeste de la Corona de Castilla", Studia Historica, Historia Medieval, VIII (1990), pp. 79-113. Precisiones estadísticas en el caso logroñés pueden verse en: DÍAZ DE DURANA, J. R. y GARCÍA FERNÁNDEZ, E., Demografía y sociedad: la población de Logroño a mediados del siglo XV. Logroño 1991.

64. GOICOLEA JULIÁN, F. J., "La expansión territorial de los núcleos urbanos y la articulación de las relaciones con sus aldeas en La Rioja Alta medieval", Anuario de Estudios Medievales, 32/1 (2002), pp. 293-331.

65. GOICOLEA, Haro, pp. 32-37. 
tes de Bilibio, que incluyó, de un lado, el rompimiento de tierras y, por otro, la autorización a los vecinos para construir corrales para el ganado. En los dos casos, se trataba de disposiciones que el concejo se vio obligado a tomar a remolque de las numerosas roturaciones ilegales que los vecinos estaban protagonizando desde los años 1440. En este ambiente de ampliación del espacio cultivado y, en general, de una ordenación más estricta de los usos del espacio, se constataba en Haro a finales del siglo XV un paisaje significativamente diversificado ${ }^{66}$.

Dentro de él, la extensión mayor con diferencia se dedicaba, desde luego, al cereal. En primer lugar, al trigo, cuyo cultivo creció en detrimento de la cebada, hasta ocupar los dos tercios del terrazgo cerealista, mientras el centeno y la avena mantenían sus proporciones entre una décima y una vigésima parte del total de los cereales. En general, las tierras dedicadas a éstos se localizaban en los pagos de la vega del río Tirón, aunque, desde mediados del siglo XV, el cereal se instaló también en los espacios roturados de Zaballa en el sur y Bilibio en el noroeste del término. El segundo cultivo en extensión, y el primero en beneficios, fue el viñedo. Ocupaba no sólo, como es regla general, los terrenos más sueltos y pedregosos, que el cereal evitaba, sino también otros más fértiles, donde, en especial, desde 1440, se plantaron, de forma continuada, nuevos majuelos. La ampliación del espacio dedicado al viñedo a finales del siglo XV es un dato comprobado tanto en la Rioja alta como en lo que hoy Ilamamos Rioja alavesa $^{67}$. Al compás de ella, se intensificó la ordenación homogénea del terrazgo con la constitución específica de pagos de viñedo, en lo que parece fueron pioneras las tierras que, en su momento, habían sido heredades de las decanías del monasterio de San Millán en el término de Haro.

El tercer elemento del paisaje del entorno de Haro lo constituían los cultivos exigentes en humedad que, en los pagos cercanos a la villa, constituían un cinturón de huertas, linares y cañamales. La tendencia a la ampliación de este espacio de huertas fue frenado por las ordenanzas concejiles de 1453, que, para preservar las extensiones convenientes al cereal, limitaron a una fanega de sembradura las heredades que los vecinos podían tener en los pagos de regadío. Precisamente, algunas de esas heredades de huerta, con las que se asociaba una amplia variedad de árboles frutales, estaban cercadas con muros y estacadas. Como se ve por los datos relativos al cultivo del viñedo y a las huertas, los decenios finales del siglo XV y el primero del siglo XVI conocieron algunos cambios significativos en

66. GOICOLEA, Haro, pp. 55-90.

67. DÍAZ DE DURANA, "La recuperación del siglo XV", pp. 97-98. La consolidación vitivinícola de las dos Riojas facilitó su conversión en abastecedoras principales de vino de los territorios vizcaíno y guipuzcoano. Nuevos datos en: SÁINZ RIPA, E., "Viñas y vinos en la comarca calceatense durante los siglos XIII, XIV y XV", Berceo, 129 (1995), pp. 113-137; GOICOLEA JULIÁN, F. J., "El vino en el mundo urbano riojano a finales de la Edad Media", En la España Medieval, 30 (2007), pp. 217-244, en particular, pp. 219-223. 
el paisaje del término de Haro. La tendencia, por encima de la dialéctica entre el cereal y el resto de las dedicaciones, subrayaba un interés por los productos comercializables. En esa misma dirección se movió la provisión de don Bernardino Fernández de Velasco, señor de la villa, que el concejo de Haro hizo suya en 1509. Por ella, de un lado, se disponía "que todos los vesinos de la dicha villa que tienen heredades ayan de poner hárboles en ellas, de mançanos e almendros e çeresos e guindales e otros hárboles de manera que las heredades de todos los términos estén pobladas de los dichos árboles". Y, de otro, el Condestable ordenaba que "se pongan en los términos de esta villa holibos en los términos que mejores sean para que se puedan haser"; $y$, para ello, se dispuso que "bayan algunas personas a tierra de Harnedo y otras partes a buscar los más que se pudieran aver".

El terrazgo del término de Haro y sus aldeas se complementaba, a efectos de dedicación económica y de paisaje, con las tierras de aprovechamiento ganadero y forestal. Dentro de ellas, se distinguían tres tipos. Los ejidos, espacios de alimentación de la cabaña ganadera, permanentemente amenazados, desde mediados del siglo $\mathrm{XV}$, por los rompimientos protagonizados por los vecinos. Las dehesas con monte de robles y encinas, sólo significativas en la zona de Bilibio aunque había otras de menor entidad en Cuzcurritilla y en la Serna. Y, por fin, los sotos, de alisos, fresnos y mimbreras, de los que los principales eran los situados a orillas del Ebro. El conjunto de estos espacios forestales no debía ser suficiente para las necesidades de la población de Haro y sus aldeas. O, al menos, no lo era para el aprovisionamiento de ciertos ejemplares de árboles cuya madera sirviera para la construcción de obras públicas como el puente. Al menos, induce a pensarlo así el hecho de que, de vez en cuando, el concejo de Haro tuviera que solicitar a la cercana villa de Peñacerrada, del otro lado del río Ebro, el arriendo de la explotación de sus montes de robles y hayas.

Del conjunto de datos relativos al tercer escenario escogido se deducen dos cosas: una, que el término de Haro ofrecía una paisaje muy diversificado, con dominio del cereal y el viñedo; y dos, más importante para un historiador, que ese paisaje se modificaba de forma significativa, si no cuantitativamente sí cualitativamente, a finales del siglo XV. En este segundo orden de cosas, es imprescindible observar dos datos. De un lado, cómo el proceso de roturaciones, signo de una presión de la población sobre el medio natural, se realizaba en beneficio del cereal, pero en parte debido al hecho de que espacios dedicados al cereal habían pasado a ser ocupados por el viñedo. Y, de otro, cómo aquella intensificación de la presión sobre el espacio, producto, en buena medida, de objetivos de comercialización, se tradujo, igualmente, en una ampliación de las tierras sujetas a regadío y, en consecuencia, en un aumento de las obras de infraestructura orientadas a aquel fin ${ }^{68}$. La circunstancia no fue, desde luego, excepcional en Haro. Por

68. GOICOLEA JULIÁN, F. J., "Mundo urbano y actividades económicas en la Rioja Alta bajomedieval", Espacio, Tiempo y Forma, Historia Medieval, 11 (1998), pp. 251-254. 
las mismas fechas, otros concejos riojanos, en especial, los de Logroño y Calahorra, trataban, igualmente, de ordenar y ampliar las posibilidades de regadío de las corrientes de agua que atravesaban sus términos respectivos.

\section{Conclusión: la evolución medieval del paisaje en la Rioja}

El conocimiento de la geografía física de la Rioja, el de las grandes líneas de su evolución histórica y el de la identidad de los agentes gestores de las modificaciones del medio natural han servido de marco de referencia para situar los datos derivados de la documentación medieval que nos permitieran presentar lo que, en principio, estimábamos podían ser tres escenarios característicos de la evolución del paisaje. Característicos por su localización geográfica (sierra, somontano, orilla del Ebro) pero también por su personalidad sociopolítica (un valle, una aldea, una villa), lo que podía hacer de ellos los representantes de otros tantos modelos de acción sobre el medio y, por tanto, de evolución del paisaje.

De lo dicho hasta aquí, me interesa deducir dos órdenes de conclusiones. El primero se refiere a las dinámicas de cambio de paisaje. El segundo a los resultados de esos cambios. Por lo que se refiere a las dinámicas, hay que distinguir:

a) la dinámica de construcción del espacio agrario o lo que es lo mismo la dialéctica ager versus saltus. Con una imagen dominante: esa dialéctica se tradujo en un proceso de roturaciones prácticamente continuo entre los siglos X y XV, con una interrupción aparente en la segunda mitad del siglo XIV y tres momentos álgidos (finales del siglo XI; finales del siglo XIII; segunda mitad del siglo XV). Ese proceso tuvo lugar a la escala de cada una de las entidades socioterritoriales (valles, aldeas, villas) que se fueron constituyendo en la Rioja (de ahí el interés de conocer en cada momento la identidad de los agentes con poder de actuación en el medio natural) y tuvo, sin duda, una especial repercusión paisajística en el somontano. Junto a esa imagen dominante de la roturación, habría que seguir la pista de procesos, sin duda menos relevantes pero, tal vez, significativos, de posible desecación o, al menos, regulación de las aguas de los ríos afluentes del Ebro, que, a finales del siglo XV, alcanzaron notoriedad.

b) la dinámica de modificación del espacio de ager. Una imagen general, poco matizada, tendería a subrayar dos datos, por otro lado, ciertos, del paisaje medieval de los términos de villas y aldeas riojanas: el policultivo y el dominio del cereal. Una imagen más ajustada y, sobre todo, más atenta a los cambios, observaría que esos dos datos primarios se movieron a lo largo de la Edad Media. Y lo hicieron, sobre todo, en dos direcciones. La sustitución de algunos campos de cereal por otros de viñedo, en especial, en el somontano. La ampliación del área de huertas con la consiguiente ordenación de la utilización colectiva del agua (canales, acequias, regueras, etc., compaginados con los cuérnagos molinares), en 
particular, en las tierras aluviales de los afluentes del Ebro y, en menor medida, de este mismo. Estos dos procesos parece que fueron especialmente significativos en la segunda mitad del siglo XV. Hasta el punto de que cabría decir que la recuperación demográfica y económica de la Rioja en ese siglo se hizo más en favor del viñedo que del cereal. Tal vez, porque el descenso de la extensión dedicada al cereal pudo paliarse, en parte, con la ampliación de la parte sujeta a regadío, en especial, de las huertas, como, al menos, se comprobaba en Haro, Calahorra y Logroño.

Por lo que se refiere a los resultados de los cambios en los paisajes, habría que medir puntualmente los efectos de las dos dinámicas que acabo de apuntar para proponer una distribución y evolución del paisaje en la Rioja medieval tanto en los aspectos del tiempo como en los del espacio.

a) Por lo que hace a la cronología, mi conclusión es que la Rioja fue, entre los siglos $\mathrm{X}$ y $\mathrm{XV}$, un escenario de modificaciones del medio natural que resultaron constantes en el tiempo y muy concretas en el espacio. Tales modificaciones tuvieron una dirección principal: la roturación del bosque en beneficio de la agrarización del espacio; una dirección menor: la desecación o, al menos, el control de las aguas en los cursos bajos de los ríos regionales; y unas ciertas variaciones de carácter pendular: del policultivo de subsistencia dominante en el siglo $X$ a la cerealización y viñedización de finales del siglo XIII; de ésta a la recuperación del bosque en las áreas marginales de los términos en el siglo XIV; y de ésta a un cierto policultivo de orientación comercial a finales del siglo $\mathrm{XV}$, dentro del cual, el viñedo, las huertas y frutales y hasta el olivo jugaron papeles significativos. No tanto por su extensión, siempre muy inferior a la del área cerealera, cuanto por su valor de síntoma de una economía comercializada que se alejaba de la economía de subsistencia propia del campesinado de la región.

b) Por lo que hace al espacio, por debajo de estas líneas generales o pendulares de comportamiento, los paisajes de la Rioja dejaban ver, a finales del siglo XV, características comarcales que, en buena medida, se han prolongado hasta nuestros días. Ellas dibujan los cuatro paisajes riojanos reconocibles. El de la sierra, dominio del bosque y la ganadería; el de los valles de los ríos altorriojanos, dominio del policultivo y de un equilibrio ganadería/agricultura; el del somontano, dominio del cereal y el viñedo; y el de los valles de los ríos bajorriojanos y del propio Ebro, dominio de las huertas. 